\title{
National Ignition Facility End-to-End Beamline Optical Model
}

R.J. Korniski, J.K. Lawson

This article was submitted to International Optical Design Conference, Tucson, Arizona, June 3-7, 2002

\section{January 29, 2002}

Low

Livermore

National

Laboratory 


\section{DISCLAIMER}

This document was prepared as an account of work sponsored by an agency of the United States Government. Neither the United States Government nor the University of California nor any of their employees, makes any warranty, express or implied, or assumes any legal liability or responsibility for the accuracy, completeness, or usefulness of any information, apparatus, product, or process disclosed, or represents that its use would not infringe privately owned rights. Reference herein to any specific commercial product, process, or service by trade name, trademark, manufacturer, or otherwise, does not necessarily constitute or imply its endorsement, recommendation, or favoring by the United States Government or the University of California. The views and opinions of authors expressed herein do not necessarily state or reflect those of the United States Government or the University of California, and shall not be used for advertising or product endorsement purposes.

This is a preprint of a paper intended for publication in a journal or proceedings. Since changes may be made before publication, this preprint is made available with the understanding that it will not be cited or reproduced without the permission of the author.

This report has been reproduced directly from the best available copy.

Available to DOE and DOE contractors from the Office of Scientific and Technical Information P.O. Box 62, Oak Ridge, TN 37831

Prices available from (423) 576-8401 http://apollo.osti.gov/bridge/

Available to the public from the National Technical Information Service

U.S. Department of Commerce 5285 Port Royal Rd., Springfield, VA 22161 http://www.ntis.gov/

OR

Lawrence Livermore National Laboratory Technical Information Department's Digital Library http://www.llnl.gov/tid/Library.html 


\title{
National Ignition Facility end-to-end beamline optical model
}

\author{
Ronald J. Korniski \\ Science Applications International Corporation, 9455 Towne Centre Dr., MS W-2, San Diego, California 92121 \\ 805 241-4281, 805 241-7195 fax, korniskir@saic.com \\ Janice K. Lawson \\ Lawrence Livermore National Laboratory, 7000 East Avenue, L-470, Livermore, CA 94551 \\ 925 423-2075, 925 422-4667fax, lawson3@llnl.gov
}

\begin{abstract}
The optical model of a National Ignition Facility beamline will be described and illustrated. The complexity of the optical design will be evident. The benefits of having an Endto-End optical model will be presented.

C2002 Optical Society of America

OCIS codes: (140.0140) Lasers and laser optics; (120.4820) Optical Systems
\end{abstract}

\section{Introduction}

The National Ignition Facility is a high-power solid-state laser facility being built to satisfy a wide array of user requirements. During the design process, system requirements were developed to meet the user needs. Optics were designed to meet a hierarchy of subsystem and system requirements. An integrated beamline optical model on lens design software has been developed that can verify that the optical design meets the system requirements.

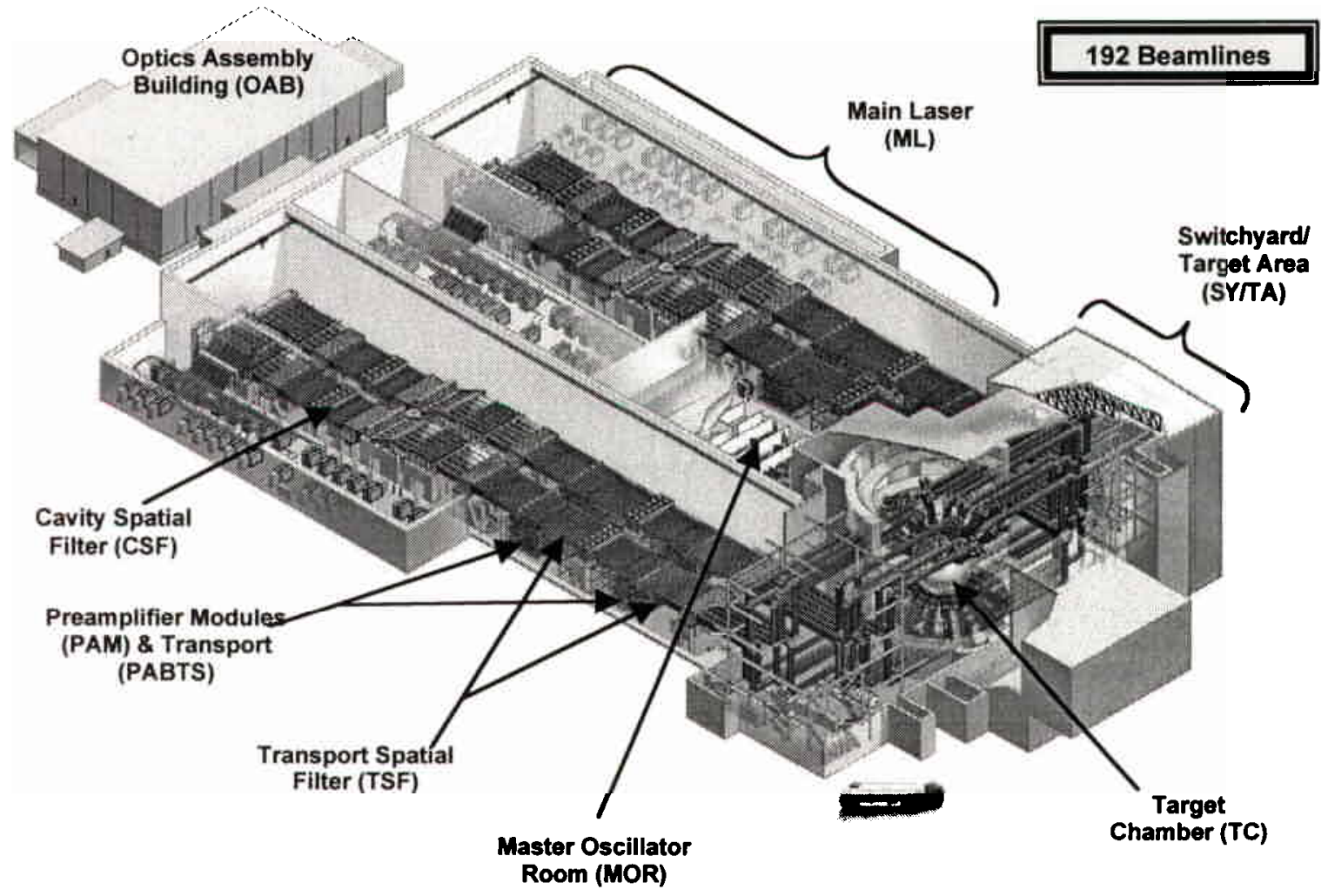

Fig. 1. Annotated view of National Ignition Facility

End-to-End Optical Model Design Overview 
An End-to-End optical model of a NIF beamline has been developed from the individual optical configuration drawings of the subsystems and element drawings. The annotated computer-generated beamline drawing below illustrates that vast distances the beamline covers relative to the apertures (Main Laser lenses are about $410 \times 410 \mathrm{~mm})$.

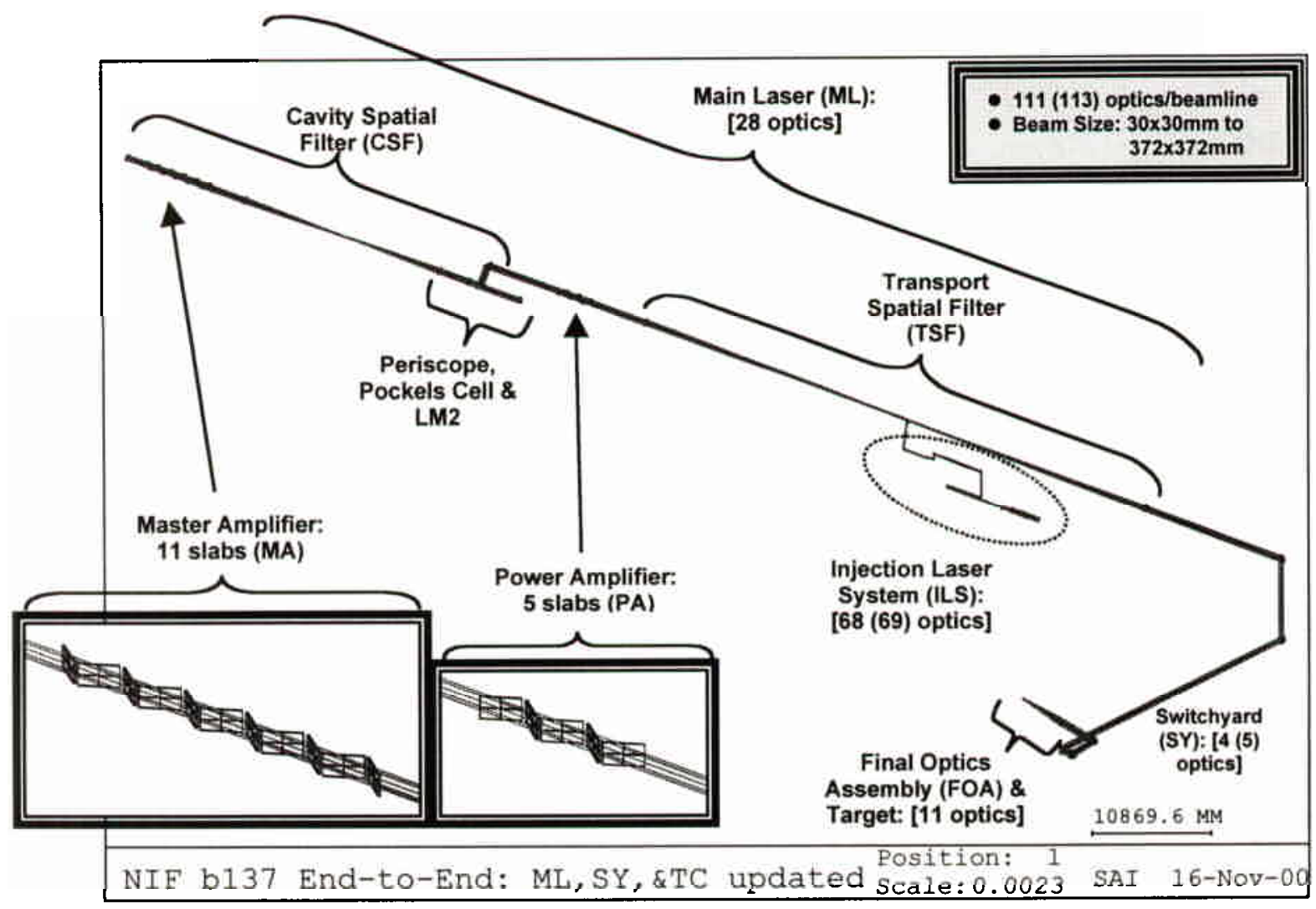

Fig. 2. Annotated plot of a beamline

The optical model consists of over 500 surfaces positioned in both local and global coordinate systems. Other salient modeling parameters are quantified in the table below. This model is a large database, but only one of 192.

Table 1. Optical model parameter summary

\begin{tabular}{|l|l|l|l|l|}
\hline \multicolumn{5}{|c|}{ Current NIF End-to-End Optical Model Details } \\
\hline Beamline & Cluster 1, Bundle 3, Beam 7 & Lines of code & $>2600$ \\
\hline Model types & Near field \& Far Field & Position definitions & $\begin{array}{l}\text { Relative \& Global (5 } \\
\text { global ones used) }\end{array}$ \\
\hline Subsystems & 8 & & Pickups & $>438$ \\
\hline Surfaces & $>525$ & $\begin{array}{l}\text { Aperture } \\
\text { specifications }\end{array}$ & $\begin{array}{l}>793 \text { (OCAs: }>236, \\
\text { Mechanical edges }>557\end{array}$ \\
\hline Surface types & $\begin{array}{l}\text { 4: flat spherical conic, } \\
\text { bilaterally symmetric } \\
\text { asphere }\end{array}$ & Wavelength & $\begin{array}{l}\text { 1053nm (frequency } \\
\text { doubling \& tripling } \\
\text { modeled as adjusted } \\
\text { refractive index) }\end{array}$ \\
\hline
\end{tabular}

The End-to-End optical model is being used to validate the flow-down assumptions mentioned above. Many optical and mechanical design aspects of the NIF beamline(s) can be explored with this type of modeling. Some total beamline characteristics that can be analyzed with such a beamline model, but not limited to, are as follows. 
1. Pupil imaging (location, magnification, and aberrations; see Relay Plane presentation for more information)

2. Total nominal beam wavefront error and geometrical spot size

3. Focus location relative to a global design coordinate reference

4. Real-ray paths

5. Optical clear apertures

6. Mechanical design checks

7. Pointing and centering needs

8. Alignment sensitivities

9. Total system tolerance analyses

\section{Additional Optical Models Considered}

One accurate and up-to-date NIF beamline optical model has proved to be invaluable. We are currently working to expand this single model into a suite of models sufficient to address optical issues that arise. Though most of the components are identical on each of the beamlines, the geometry varies from beamline to beamline to distribute 192 amplified beamlines spherically around the target. Other beamline optical models will be constructed as required to validate the mechanical model and address optical issues.

Identified beamline uniqueness sources (occurrences), both mechanical and optical:

- Switchyard (192)

- Main Laser Diagnostic Beamsplitter (2)

- Transport Spatial Filter [TSF] Lenses SF3 \& SF4 (2)

- Main Laser Periscope (4)

- Injection Lens Window (4)

- Preamplifier Beam Transport System [PABTS]/Injection System [INJSYS] paths

- Injection feed to TSF (2)

- $1: 4$ beam split (4)

- Injection Laser System aiming (2)

- PABTS vacuum relay telescope [VRT] (4-7)

- $\quad$ PABTS trombone timing (192)

\section{Summary}

The current End-to-End NIF beamline optical model is a living one. Revisions to the beamline database is ongoing both from mechanical and optical considerations. To date the End-to-End optical model has been used to verify the following aspects of a NIF beamline.

- Impact on critical clear apertures in the Master Amplifier for pupil location variation

- Main Laser tilt adjustments to achieve Pointing and Centering from nominal subsystem positioning and ramifications of Injection Laser System positioning

- Definition and location of the last pupil (relayed aperture plane, see Relay Plane presentation for more information on this complex issue)

- Switchyard mirror orientations

- Focus on target and final wavefront error

- Conjugate location of Deformable Mirror (LM1) in the Injection Laser System

- Exiting beam characteristics from the Main Laser into the Switchyard (intercepts and angular)

- Beam residual deflection of "compensated" wedged optical components

Various other evaluations are planned and more are coming to light.

This work was performed under the auspices of the U. S. Department of Energy by the University of California, Lawrence Livermore National Laboratory under Contract No. W-7405-Eng-48. 